\section{FOOD HYGIENE}

$\mathrm{P}^{\mathrm{F}}$ ROBLEMS of hygiene in the preparation, distribution and serving of food were the subject of discussion at a joint meeting of the Society for Applied Bacteriology and the Microbiological Panel of the Food Group of the Society of Chemical Industry, which was held in London in January last. Papers were read by Dr. W. A. Lethem, principal medical officer of the Ministry of Food, Dr. Betty C. Hobbs, of the Central Public Health Laboratory, London, and by Mr. D. H. F. Clayson, of Messrs. Lyons and Co., Ltd. These papers will be published in full in the Proceedings of the Society for Applied Bacteriology.

Dr. Leth $\mathrm{m}$ gave a short introduction to the symposium by dealing with the legislative aspects of the problems. He pointed out that the Ministry of Food acts largely in an advisory capacity and is mainly concerned with the drafting of regulations and model by-laws covering the hygienic handling and sale of food. The enforcement of legislation has always been, and still is, a matter for each particular local authority. In addition to helping local authorities in every way possible, the Ministry aims by wide propaganda at arousing public opinion so that a demand for hygienic measures in food matters should come from the consumer. On the question as to whether existing powers are sufficient to enforce an improvement in present-day standards, it is felt that in general the powers are adequate, although there is room for more in certain directions, such as in the control of open-air stalls and barrows. There is a striking difference between the extent and effectiveness of enforcement by different local authorities throughout Great Britain ; but, in general, improvements are being made. The general standard of food hygiene in Great Britain is low enough to be a shock to visitors from some overseas countries.

Dealing with laboratory control of food hygiene, Dr. Hobbs outlined the chain of infection from human and animal reservoirs through handling and storage of the food to its consumption. Effective control would arise from breaking this chain at one or more links. Figures were given showing $\boldsymbol{a}_{\mathrm{b}}$ definite increase in the number of outbreaks of food-borne infection over the past few years, and it was explained that this is attributable to an increase in communal feeding on one hand, and improved facilities for laboratory diagnosis of the etiology of the infections on the other.

With the exception of the Salmonella group causing the 'infection' type of food poisoning, many of which naturally infect domestic animals and vermin, and some of the anaerobic spore-bearing bacilli, man is the main reservoir of bacteria causing gastro-enteritis. Salmonella, including typhoid and paratyphoid bacilli, and dysentery bacilli may be transferred to food from human excreta via the hands of food handlers who are acute or convalescent cases or are symptomless chronic carriers.

The persistence of the chronic carrier state in the case of the enteric group of organisms is to be measured by years, and, although true carrier states following other Salmonella infections and bacillary dysentery are less common, there is evidence available to show that persistence can be considerable. Bacteriophage typing has proved invaluable in the laboratory for tracing cases and carriers associated with outbreaks of typhoid and some Salmonella infections.
Rat and mouse droppings may contaminate food with Salmonella, and certain rat poisons containing living Salmonella are potentially dangerous in food premises. Duck eggs are prone to infection from the oviduct with $S$. typhi-murium, and hen eggs may be contaminated externally with food-poisoning organisms from fæces in the nest. Lightly cooked egg dishes from whole or reconstituted dried egg may thus be responsible for food poisoning. Flies are potential carriers of contamination, both on their feet and in their fæces; but in Great Britain at the present time this vector may be considered to be of fairly low significance.

The 'toxin' type of food poisoning is most commonly caused by the development in the stored food of enterotoxins of certain pathogenic staphylococci. Fifty to sixty per cent of normal healthy people carry pathogenic staphylococei in the nose, and fifteen to twenty per cent are persistent hand-carriers of these organisms. Not all these staphylococci are able to produce enterotoxin in food. One or two serological and bacteriophage groups seem to be responsible, and laboratory diagnosis of the reservoir of infection is based on these methods of typing. The organisms are transferred from the hands to cooked foods during handling, and intoxication occurs when such foods are eaten cold at a later stage. The toxin resists boiling for twenty to thirty minutes, and, apart from human volunteers, no method is available to detect the toxin in food which has been heated enough to destroy the organisms but not the toxin.

Among the kinds of food most often involved in outbreaks of gastro-enteritis, by far the most common are made-up meat dishes, such as pies, pressed beef, brawns, hams and sausages; made-up fish dishes, puddings and other sweets, fresh and tinned milk, fresh and dried eggs, soups, stews, gravies and the like are also commonly involved. Following contamination of the food, there is usually necessary an incubation period for the multiplication of the bacteria or the development of the toxin. Here, time, temperature and moisture content of the food are the significant factors. Development of the food to an infectious stage is largely prevented by a short. time of storage at a low temperature.

In addition to Salmonella and staphylococci described above, within the past year or two, three. or more groups of organisms have been proved by human volunteer experiments to be the cause of gastro-enteritis. $\alpha$-Hæmolytic streptococci, paracolon bacilli and certain types of Clostridium welchii have been incriminated in a few outbreaks. These strains. of Clostridium welchii seem to differ from the known types, particularly in their resistance to heat. The source of the organism is not yet known.

Mr. Clayson pointed out that there is no essential: difference between the laboratory and practical aspects of food hygiene. In order to prevent foodborne infections, one must know how they are caused. and how the causative organisms can be eliminated. Little purpose is served by the routine examination of processed foods for pathogens ; but it is important. to ensure by bacteriological tests for index organisms, by plate counte and by appropriate physical tests. that the process used is adequate to eliminate pathogens. From time to time, unsuspected organisms. turn out to be pathogenic, and a theoretically sound process affords protection in all cases.

Bacteriological tests should not form the whole basis of an inspection programme. Visible dirt must be eliminated, since there may be opportunities for 
the transfer of such dirt to food in the vicinity, for example, by draughts, insects, or contact with hands or clothing. A sense of hygiene must be inculcated into those concerned with food preparation and service, and lectures and demonstrations play an important part in their education. This must be supplemented by a comprehensive system of inspection and correction of faults if and when they occur. The principles of hygiene are not always easy to work out in practice, and frequent discussions with managerial staff regarding improvements of method are invaluable.

The hygienic precautions required in the preparation of food vary with perishability. In some instances handling is best avoided, whereas foods with comparatively dry external surfaces are not liable to become unsafe if handled. Perishability is related to the physical and chemical characteristics of the environment surrounding the contaminating organisms, but owing to the heterogeneous nature of most foods there is often a range of conditions in any one article. If preparation processes involve more than one stage, any bacterial contamination during early manipulation must be destroyed in the final stages, or prevented from increasing by refrigeration or other means if a final bactericidal treatment is impracticable.

In the service of food, much attention has been given to the cleaning and sterilizing of crockery and cutlery. It is also important to avoid deterioration of food through faulty estimation of requirements. Such deterioration can be avoided by preparing food in small units, by minimizing manipulation during service, by using food in correct order and by intelligent use of refrigeration.

T. RICHARDS

\section{BERNARD DYER AND AGRICULTURAL CHEMISTRY}

GIR JOHN RUSSELL, in delivering the first $\checkmark$ Bernard Dyer Memorial Lecture of the Society of Public Analysts and Other Analytical Chemists*, paid a tribute to Dyer's high analytical attainments, intellectual honesty, human sympathy and the ready helpfulness that he invariably showed to younger colleagues. Sir John continued by giving many interesting but little-known biographical details of Dyer's early life and experiences in founding and consolidating an important analytical and consulting practice in agricultural chemistry.

When but twenty-one years of age, in 1877, he had set up in practice at 17 Great Tower Street, London, where he remained until the building was destroyed by a German bomb in May 1941. Here, he rapidly built up a reputation as an agricultural chemist of ability.

$\mathrm{His}$ work on the determination of available phosphorus and potassium by means of preliminary extraction with a 1 per cent solution of citric acid was among the earliest of his analytical achievements. This work formed the subject of a thesis on which the University of London in 1892 awarded him the degree of D.Sc. ; later, in 1894, it was published by the Chemical Society. Lawes and Gilbert, realizing the nature of this work, invited Dyer to make a full examination of the soils of the famous Broadbalk

* The First Bernard Dyer Memorial Lecture, delivered by Sir John of Public Analysts and Other Analytical Chemists, on March 17. wheat field at Rothamsted. This he did, and the results obtained by the citric acid method accorded well with the field experiments. The paper on this work was presented to the Royal Society and published in the Philosophical Transactions.

But Dyer did not occupy himself entirely with laboratory work and investigation into analytical methods. He saw clearly that if chemistry was to be of real help to agriculture it could only be through the closest association between the laboratory and the farm. With this object he went among the farmers and with their help conducted experiments in the fields. In all his field experiments he invariably dealt with some definite question of practical importance put to him by the farmers themselves. 'His part was to devise simple straightforward experiments that gave the required answer and to write a report in language that the farmers could understand.

Meanwhile soil investigation was continuing and was extended in England when the Goldsmiths' Company, in 1906, endowed a research post at Rothamsted, and still more so when the Development Commission, from 1911 onwards, made grants for agricultural research, which finally led to the formation of the Agricultural Research Council. These extended investigations showed the great complexity of the phosphorus and potassium compounds in the soil.

Moreover, Sir John continued, the processes by which the plant roots take up their nutrients from the soil had been shown to be much more complex than was at first thought, and that what is 'available' to one plant may not be 'available' to another.

The present-day problem was to find analytical methods that would give some measure of the amount of nutrients that crops could, under normal conditions, obtain from the soil. Dyer's method came into wide but not universal use. Other solvents, in steadily increasing numbers, had been proposed, but no two gave the same results. Curves expressing the results could be fitted by no ordinary equation. This problem was taken up at Rothamsted by J. A. Prescott and Sir John himself, who found that when dilute acids acted on soils, two reactions proceeded simultaneously : the acid dissolved phosphate, but the soil slowly absorbed it from the solution. This back-action was eliminated by using a diffusion technique, which showed that tenth-normal citric, hydrochloric and nitric acids all extracted the $\operatorname{sam} \theta$ amount of phosphorus, whereas by the ordinary analytical method the citric acid extracted nearly twice as much as the hydrochloric acid and fifty per cent more than the nitric acid. The citric acid had done this because it had reduced the difference between the amount extracted by the acid and the amount re-absorbed by the soil. Only the direct action was wanted by the analyst; the second action upset his results. So long as he was dealing with similar soils he could assume that the reverse action was also somewhat similar and that his results would still be comparable, but when he was dealing with different soils the reverse action might be different and he might get different analytical results even though the same amounts of phosphorus had been extracted. It was concluded, therefore, that soil analysis could be helpful when used in conjunction with a soil survey showing the areas of comparable soils, but that standards applied to one soil could not necessarily be applied to another.

Modern developments in technique had profoundly changed the whole subject. Citric acid long 